\title{
Interaction between Triticum aestivum Plants and Four Fusarium Head Blight Species on the Level of Pathogenicity: Detected in an in vitro Petri-dish Assay
}

\author{
N. SAKR \\ Department of Agriculture, Atomic Energy Commission of Syria (AECS), Damascus, P.O. Box 6091, Syria
}

(Received: 17 May 2018; accepted: 29 May 2018)

\begin{abstract}
The interaction between bread wheat (Triticum aestivum L.) plants and four filamentous species of the Fusarium genus (the causal agent of Fusarium head blight, FHB) was analyzed in an in vitro Petri-dish assay. Pathogenicity criteria as well as germination rate reduction, standardized area under disease progress curve $\left(\mathrm{AUDPC}_{\text {standard }}\right)$, and coleoptile length reduction were investigated in seeds and six-day-old seedlings showing a moderately level of quantitative resistance, after inoculations with 16 FHB isolates. AUDPC standard $_{\text {f }}$ did differentiate FHB isolates and the other two pathogenicity criteria did not. It was not possible to cluster the isolates based on their species origins because of similarity in pathogenic level among the 16 fungal isolates. Cultivar-specific pathogenicity has been detected. The values of disease incidence and disease severity involved in previous artificial head and floret inoculations showed significant correlation with $\mathrm{AUDPC}_{\text {standard }}$ : $\mathrm{r}=0.653^{* *}$ and $\mathrm{r}=0.559^{*}$, respectively. $\mathrm{AUDPC}_{\text {standard }}$ could be of potential use in evaluating the pathogenicity of FHB in adult wheat plants.
\end{abstract}

Keywords: Bread wheat cultivar, FHB variation, plant-pathogen interaction.

Triticum is a genus of the family Poaceae (grass family). It is native to the Mediterranean region and Southwest Asia in which the archaeological evidence of its cultivation took place to 9,600 B.C. in the Fertile Crescent. Bread wheat (T. aestivum Lersten, $2 n=6 x=42$ AABBDD) is an important cereal crop and now grown in temperate climates worldwide. This type of wheat is preferred for bread production due to the viscoelastic properties of its endosperm gluten proteins, representing the food basis for civilization development (de Oliveira et al., 2014). The seed infection by filamentous pathogens of the Fusarium genus is a great risk for wheat cultivation. Fusarium species are widespread pathogenic fungi which can cause Fusarium head blight (FHB).

FHB or head scab is a devastating disease of wheat, barley and other small grains in many regions of the world. It has re-emerged as a major threat to cereal crops in temperate areas in which warm moist weather conditions are favorable for disease development (Parry et al., 1995). This pathogen infects the head during anthesis with colonization of anthers, stigmas, and lodicules first. It is followed by penetration of floral tissues and spread from spikelet to spikelet through the vascular tissue in the rachis and

*E-mail: ascientific@aec.org.sy 
rachilla, ultimately resulting in bleaching of the whole spike (Bushnell et al., 2003). FHB cause quantitative yield losses of up to $50 \%$ and reduces grain quality because of contamination with harmful trichothecene mycotoxins to humans and animals (Dahl and Wilson, 2018).

Seventeen filamentous species of the Fusarium genus are known to contribute to FHB disease. F. graminearum is the most common causal agent of FHB in many parts of the world. Also, other FHB pathogens are less isolated frequently from FHB infected kernels such F. pseudograminearum, F. culmorum, F. avenaceum, F. equiseti, F. verticillioides and F. poae (Parry et al., 1995; Kiseleva et al., 2016). The spectrum of Fusarium sp. involved in the disease varies at a local or regional level depending on specific climatic conditions, agricultural practices, effectiveness of fungicides used and host resistance (Dahl and Wilson, 2018).

Pathogenicity is an attribute of a pathogen originally defined as non-specific, disease-causing abilities of a causal agent. Diversity in pathogenicity among FHB isolates recovered worldwide within a country and even within populations from individual fields has been the subject of several studies (Xu and Nicholson, 2009). In a given individual field, different levels of pathogenicity are observed for several isolates in a given filamentous Fusarium species, so the pathogenicity is not geographically structured. Resistance to FHB is a complex and quantitative trait modulated by multiple genetic factors in wheat gene pool (Steiner et al., 2017). Quantitative resistance is largely pathotype nonspecific, although some quantitative trait loci (QTLs) were shown to be isolate specific (Romero et al., 2018). Parry et al. (1995) showed no strong evidence for cultivar-specific pathogenicity in the filamentous FHB complex.

In Syria, wheat is one of the most important crops occupying up to $24 \%$ of the cultivated area, with an annual production of 3.9 million tons in 2011 (FAO/WFP, 2015). Bread wheat is cultivated primarily in irrigated areas. Syria is located in the "center of origin' of wheat. Thereby, Syrian wheat cultivars constitute a valuable genetic resource, possessing various desirable agronomic traits, including acceptable-level resistance to FHB. Indeed, some in vitro and growth chamber studies have reported the evaluation of pathogenicity of Syrian filamentous FHB pathogens and resistance of local wheat and barley cultivars (Alazem, 2007; Bakri et al., 2012; Sakr, 2017a, 2017b, 2018a, 2018b, 2018c).

Ideally, two or more tests should be conducted and the data should be compared to check whether the ranking in pathogenicity is constant. However, there are only some reports that use more than one test to assess pathogenicity of the fungal isolates (Purahong et al., 2012; Sakr 2017a). The aims of this present study were to (1) investigate the interaction between Syrian bread wheat plants and four filamentous FHB species on the level of pathogenicity in an in vitro Petri-dish assay, and to (2) examine the relationship between in vitro and in previous in planta artificial head and floret inoculations data.

\section{Materials and Methods}

\section{Filamentous fungal isolates}

The 16 FHB isolates of four Fusarium sp. (F. culmorum (F1, F2, F3, F28 and F30), F. verticillioides (F15, F16, F21 and F27), F. solani (F7, F20, F26, F29, F31 and F35), 
and F. equiseti (F43)) were collected in 2015 from naturally wheat spikes exhibiting FHB symptoms from Ghab Plain, one of the principal wheat Syrian production areas.

On potato-dextrose agar, fungal colonies were identified to species by microscopic observations of sporulation shape and type (spores and phailides morphology), along with optical observations of the cultural characteristics, such as colony shape and morphology, pigmentation and density of aerial and medial mycelium (Nelson et al., 1983). For long term preservation, fungal cultures were maintained in sterile distilled water at $4{ }^{\circ} \mathrm{C}$ and freezing at $-16{ }^{\circ} \mathrm{C}$ (Sakr, 2018d).

\section{Triticum aestivum plants}

Syrian bread wheat Douma4 with highest agronomic traits and resistance to fungal diseases is widely cultivated in Ghab Plain. A moderately resistance level was observed for Douma4 in vitro (Sakr, 2017b) and under controlled conditions (Sakr, 2017a).

\section{Pathogenicity tests}

Three pathogenicity criteria: germination rate reduction, standardized area under disease progress curve $\left(\mathrm{AUDPC}_{\text {standard }}\right)$, and coleoptile length reduction were involved in a Petri-dish test described by Purahong et al. (2012) for F. graminearum. Sterilized wheat seeds of Douma4 were inoculated with a suspension of conidia (at $1 \times 10^{6}$ conidia per ml or sterile distilled water in the control treatment) for 16 fungal isolates in Petri-dishes with sterile double-layer filter paper, and arranged in a complete randomized design with three replicates. Three Petri-dishes per replicate were left non-inoculated as a control treatment. Three replicates of each isolate were set up and the experiment was repeated. Infected and control treatments were incubated in an incubator at $22{ }^{\circ} \mathrm{C}$ in the dark. Germination rate reduction and coleoptile length reduction were determined by comparison with the control treatment at 6 days after inoculation. The value of $\mathrm{AUDPC}_{\text {standard }}$ ranges from 0 (not pathogenic) to 1 (very pathogenic), and it was calculated from the percentage of healthy coleoptiles as a function of time (from 2 to 6 days after inoculation).

\section{Statistical analyses}

Data were performed using StatView, $4.57^{\circledR}$ Abacus. ANOVA incorporating the Fisher's LSD test at $\mathrm{p}=0.05$ was used to differentiate pathogenicity of 16 FHB isolates. The sample correlation coefficients (Pearson $r$ ) were calculated using overall values per isolates at $\mathrm{p}=0.05$ and $\mathrm{p}=0.01$.

\section{Results and Discussion}

Compared to the water control, seedling of Douma4 plants growing in the presence of 16 filamentous tested isolates showed typical in vitro FHB symptoms according to a Petri-dish test (Fig. 1) (Purahong et al., 2012; Sakr, 2017b, 2018a, 2018b, 2018c). This test provides different experimental conditions for FHB species to develop the symptoms, thus ensure that their pathogenicity is stable and/or correctly characterized or quantified. 


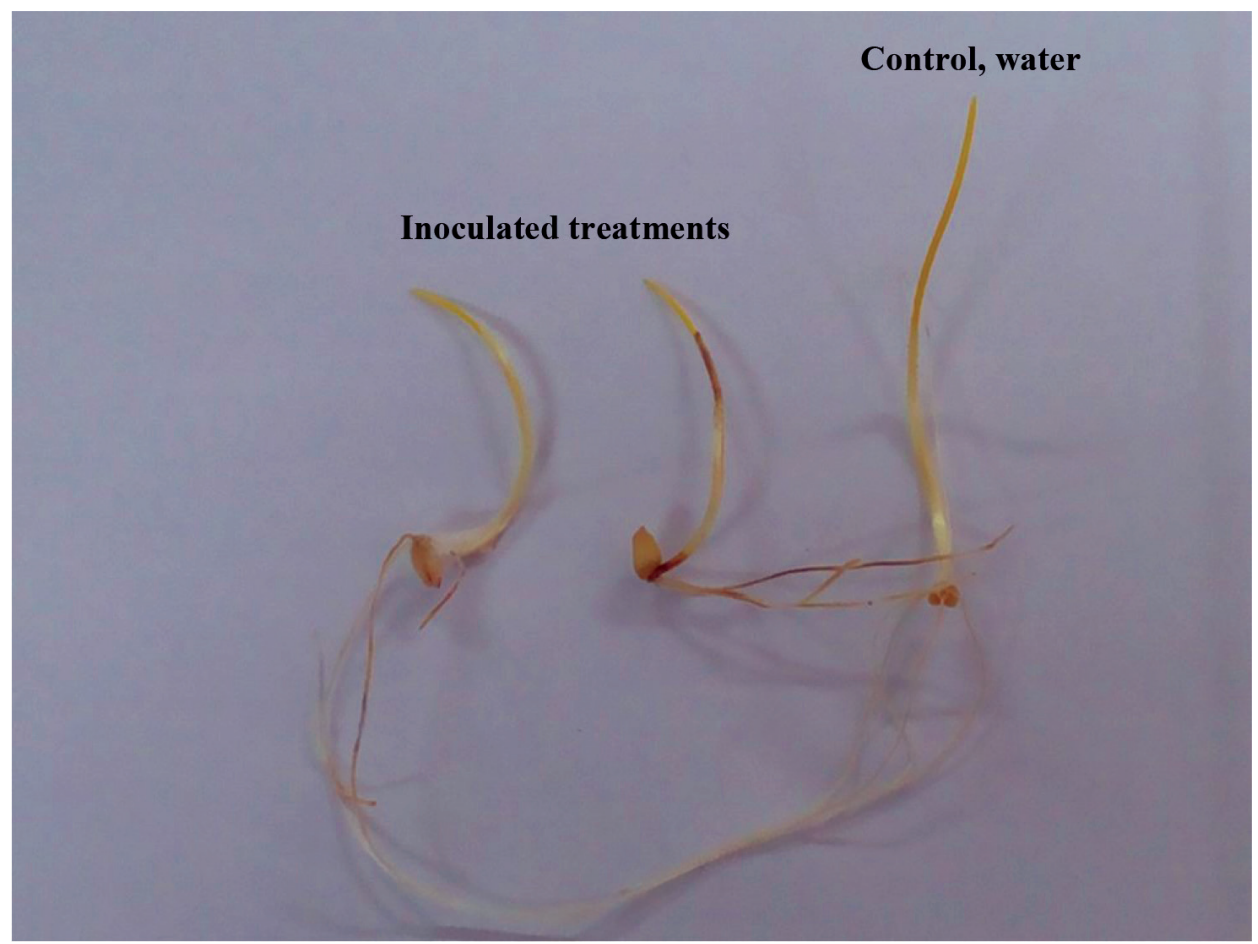

Fig. 1. Fusarium head blight symptoms on seedlings of Triticum aestivum wheat cultivar Douma4 inoculated with isolate F1 (Fusarium culmorum) as compared to control (water treated) at 6 days after inoculation

All the fungal isolates analyzed with the in vitro Petri-dish assay fulfilled the requirement of pathogenicity (capacity to induce FHB disease), thus they are pathogenic. The capacity of 16 fungal isolates to cause necrosis in different amounts on wheat seedlings may be due to that the four FHB species involved in this study produce different mycotoxins which have been found to cause symptoms in plant tissues (Xu and Nicholson, 2009).

Germinated wheat seeds in inoculation treatments decreased significantly by fifth compared with the control. The mean value of germination rate reduction (GRR) ranged from 18 to $23 \%$ (Table 1). Diseased coleoptiles were only one half of mean lengths of healthy coleoptiles that reached $10.6 \mathrm{~mm}$ on Douma4 whatever was FHB isolate. The mean values of coleoptile length reduction (CLR) varied between 52 to $57 \%$ (Table 1). For these two pathogenicity criteria, there were no significant differences within and among the four FHB species (Table 1). Our results agree with in vitro previous GRR and CLR analyses in which those two pathogenicity criteria did not distinguish FHB isolates on wheat and barley plants (Sakr, 2017b, 2018a, 2018b, 2018c). Also, our results regarding GRR correspond to those reported by Purahong et al. (2012). However, CLR caused by F. graminearum has been related to pathogenicity (Brennan et al., 2003). Purahong et al. (2012) found that this parameter distinguished isolates. The values of AUDPC $_{\text {standard }}$ (from 0.25 for 0.59 ) underlined diversity in pathogenicity within and among four FHB species

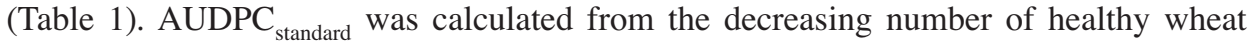
seedlings after fungal inoculation of the seeds (Purahong et al., 2012). The faster the re- 
Table 1

Pathogenicity within and among four filamentous Fusarium head blight species measured on Triticum aestivum wheat cultivar Douma4

\begin{tabular}{|c|c|c|c|}
\hline $\begin{array}{l}\text { Fungal isolates } \\
\text { (identification) }\end{array}$ & Germination rate reduction $(\%)$ & AUDPC $_{\text {standard }}$ & $\begin{array}{l}\text { Coleoptile length reduction } \\
(\%)\end{array}$ \\
\hline$\overline{\mathrm{F} 1^{\mathrm{Fc}}}$ & $22 \mathrm{aA}$ & $0.34 \mathrm{cFG}$ & $57 \mathrm{aA}$ \\
\hline $\mathrm{F} 2^{\mathrm{Fc}}$ & $22 \mathrm{aA}$ & 0.49abBCD & $58 \mathrm{aA}$ \\
\hline $\mathrm{F} 3^{\mathrm{Fc}}$ & $20 \mathrm{aA}$ & $0.59 \mathrm{aA}$ & $57 \mathrm{aA}$ \\
\hline $\mathrm{F} 28^{\mathrm{Fc}}$ & $23 \mathrm{aA}$ & $0.44 \mathrm{bcCDE}$ & $57 \mathrm{aA}$ \\
\hline \multirow[t]{2}{*}{$\mathrm{F} 30^{\mathrm{Fc}}$} & $23 \mathrm{aA}$ & $0.44 \mathrm{bcCDE}$ & $52 \mathrm{aA}$ \\
\hline & $\mathrm{P}=0.5986$ & $\mathrm{P}=0.0230$ & $\mathrm{P}=0.7224$ \\
\hline $\mathrm{F} 7^{\mathrm{Fs}}$ & $20 \mathrm{aA}$ & $0.45 \mathrm{cCDE}$ & $56 \mathrm{aA}$ \\
\hline $\mathrm{F} 20^{\mathrm{Fs}}$ & $23 \mathrm{aA}$ & $0.45 \mathrm{cCDE}$ & $55 \mathrm{aA}$ \\
\hline $\mathrm{F} 26^{\mathrm{Fs}}$ & $19 \mathrm{aA}$ & $0.50 \mathrm{bABC}$ & $58 \mathrm{aA}$ \\
\hline $\mathrm{F} 29^{\mathrm{Fs}}$ & $20 \mathrm{aA}$ & $0.28 \mathrm{dGH}$ & $58 \mathrm{aA}$ \\
\hline $\mathrm{F} 31^{\mathrm{Fs}}$ & $20 \mathrm{aA}$ & $0.45 \mathrm{cCDE}$ & $59 \mathrm{aA}$ \\
\hline \multirow[t]{2}{*}{$\mathrm{F} 35^{\mathrm{Fs}}$} & $19 \mathrm{aA}$ & $0.56 \mathrm{aAB}$ & $56 \mathrm{aA}$ \\
\hline & $\mathrm{P}=0.9860$ & $\mathrm{P}=0.0001$ & $\mathrm{P}=0.9393$ \\
\hline $\mathrm{F} 15^{\mathrm{Fv}}$ & $18 \mathrm{aA}$ & $0.25 \mathrm{cH}$ & $57 \mathrm{aA}$ \\
\hline $\mathrm{F} 16^{\mathrm{Fv}}$ & $20 \mathrm{aA}$ & $0.49 \mathrm{aBCD}$ & $59 \mathrm{aA}$ \\
\hline $\mathrm{F} 21^{\mathrm{Fv}}$ & $19 \mathrm{aA}$ & $0.37 \mathrm{bEF}$ & $59 \mathrm{aA}$ \\
\hline \multirow[t]{2}{*}{$\mathrm{F} 27^{\mathrm{Fv}}$} & $19 \mathrm{aA}$ & $0.41 \mathrm{bDEF}$ & $55 \mathrm{aA}$ \\
\hline & $\mathrm{P}=0.9383$ & $\mathrm{P}=0.0001$ & $\mathrm{P}=0.8676$ \\
\hline $\mathrm{F} 43^{\mathrm{Fe}}$ & $0.22 \mathrm{aA}$ & $0.48 \mathrm{BCD}$ & $0.55 \mathrm{aA}$ \\
\hline Enter isolates & $\mathrm{P}=0.9959$ & $\mathrm{P}=0.0001$ & $\mathrm{P}=0.9929$ \\
\hline
\end{tabular}

Fungal identification: ${ }^{\mathrm{Fc}}$ Fusarium culmorum, ${ }^{\mathrm{Fs}} \mathrm{F}$. solani, ${ }^{\mathrm{Fv}}$ F. verticillioides and ${ }^{\mathrm{Fe}}$ F. equiseti. According to the Fisher's LSD test, means followed by the same letter are not significantly different at $\mathrm{p}=0.05$ (small letters refer to aggressiveness within species and capital letters to aggressiveness between isolates of species), Probability (P). In the current study, isolates F2, F35, F27 and F43 were reanalyzed for aggressiveness test on Douma4, however, pathogenic reaction for the four isolates was analyzed previously and presented by Sakr (2017b)

duction of the number of healthy seedlings, the more pathogenic is the fungal isolate $(\mathrm{Pu}-$ rahong et al., 2012). The wide range of variability of pathogenicity among FHB isolates in our study has been supported by other studies investigating pathogenicity of $F$. graminearum and the same tested fungal isolates using $\mathrm{AUDPC}_{\text {standard }}$ criterion on wheat and barley plants (Purahong et al., 2012; Sakr, 2017b, 2018a, 2018b, 2018c). Mutation, genetic recombination or selection may play a basic role in these differences in pathogenicity.

The three criteria obtained with the Petri-dish test were not significantly correlated, suggesting that these criteria are genetically distinct, and also reflecting into complex polygenic nature of pathogenicity in the interaction in filamentous FHP-wheat system. There was no correlation between GRR and both: $\operatorname{AUDPC}_{\text {standard }}(\mathrm{r}=0.148$ not significant $)$ and CLR ( $r=0.141$ not significant). No correlation was detected between AUDPC $\mathrm{Atandard}_{\text {and }}$ CLR ( $r=-0.212$ not significant). However, our results do not correspond with those obtained by Purahong et al. (2012). They noticed a correlation among all pathogenicity parameters. Our data agree with those found by Sakr (2018a, 2018b) on wheat and barley plants.

More interesting is the fact that, our results were not comparable with in vitro previous $\mathrm{AUDPC}_{\text {standard }}$ analyses obtained using the same fungal isolates on wheat durum culti- 
$\operatorname{var}$ Cham7 ( $\mathrm{r}=0.302$ not significant, Sakr, unpublished data) in vitro (Fig. 2). A possibility of a minor gene-for-minor gene interaction exists between the two bread and durum wheat cultivars and 16 filamentous fungal isolates. Polygenic quantitative resistance is usually supposed to be non-race specific, but does not appear to be so. It seems that certain minor QTLs genes might not effective to all FHB isolates. In this pathosystem, no strong evidence for specific pathogenicity interactions among fungal species implicated in the FHB complex and wheat plants (Parry et al., 1995). Such small cultivar-isolate interactions have been reported for Blumeria graminis/barley pathosystem (Romero et al., 2018).

The significant reductions observed with germination rate and coleoptile length, and significant increases with AUDPC are an indication of pathogenicity (Purahong et al., 2012). Results shown in Table 1 indicated that AUDPC $_{\text {standard }}$ parameter can differentiate within and among differences in pathogenicity in four FHB species. Within F. culmorum species, F1 gave the least AUDPC $_{\text {standard }}(0.34)$, while F3 (0.59) was significantly more pathogenic. Within $F$. solani species, the lowest AUDPC $_{\text {standard }}$ value $(0.45)$ occurred for F7, F20 and F31, whereas the most pathogenic isolate F35, with value (0.56). Within F. verticillioides species, the least $\mathrm{AUDPC}_{\text {standard }}$ value was for F15 (0.25), and the most pathogenic isolate was F16 (0.49). Our results are comparable with those found by Sakr (2017b, 2018a,b) on wheat and barley by using the same fungal isolates. Moreover, significant differences were detected within three Syrian FHB species F. culmorum, F. solani and $F$. verticillioides collected from different Syrian regions under controlled conditions (Bakri et al., 2012). There were significant differences in the variation of pathogenicity among the isolates from the four FHB species, the isolate F3 (F. culmorum) showed the greatest pathogenic, while F15 (F. verticillioides) was the least pathogenic isolates (Table 1). However, the AUDPC $_{\text {standard }}$ differences among 16 isolates cannot be used to distinguish the four filamentous FHB species, for example, isolates F28 and F30 (F. culmorum), F7, F20 and F31 (F. solani), F16 and F27 (F. verticillioides), and F43 (F. equiseti) were not significantly different (Table 1). It was not possible to cluster the filamentous isolates based on their species origins because of similarity in pathogenic level among

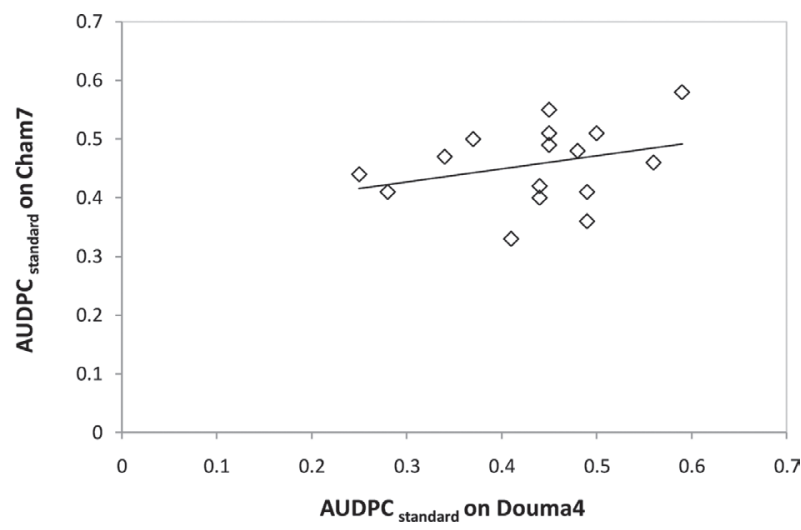

Fig. 2. Correlation between standardized area under disease progress curve (AUDPC standard ) on two Triticum sp. wheat cultivars: Douma4, bread wheat (data presented in this study) and Cham7, durum wheat (Sakr, unpublished data) infected with 16 fungal isolates of four filamentous Fusarium head blight species determined by Pearson correlation coefficient, $r=0.302$ not significant 
the 16 fungal isolates (Fig. 3). The origin of FHB cultures may play a crucial role in this pathogenic similarity (Sakr, 2018a).

Our results showed that the moderately resistance level in Douma4 made it possible to detect intra- and inter-significant differences in pathogenicity. These results supported

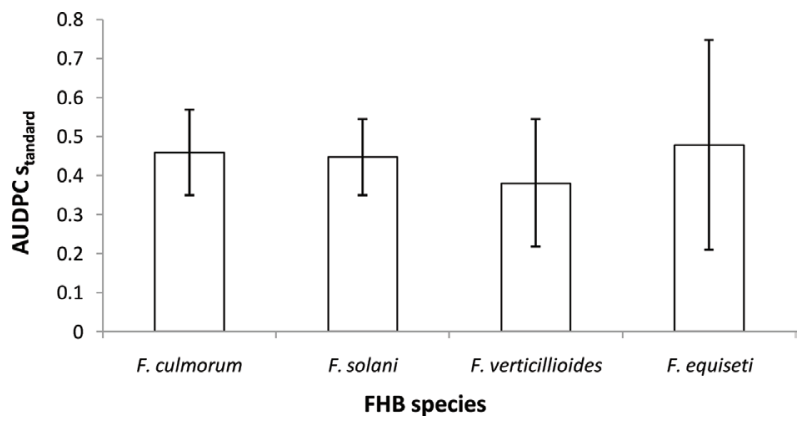

Fig. 3. Mean standardized area under disease progress curve $\left(\mathrm{AUDPC}_{\text {standard }}\right)$ of four filamentous Fusarium head blight species on Triticum aestivum wheat cultivar Douma4 detected in an in vitro Petri-dish assay. Bars represent the standard errors of means
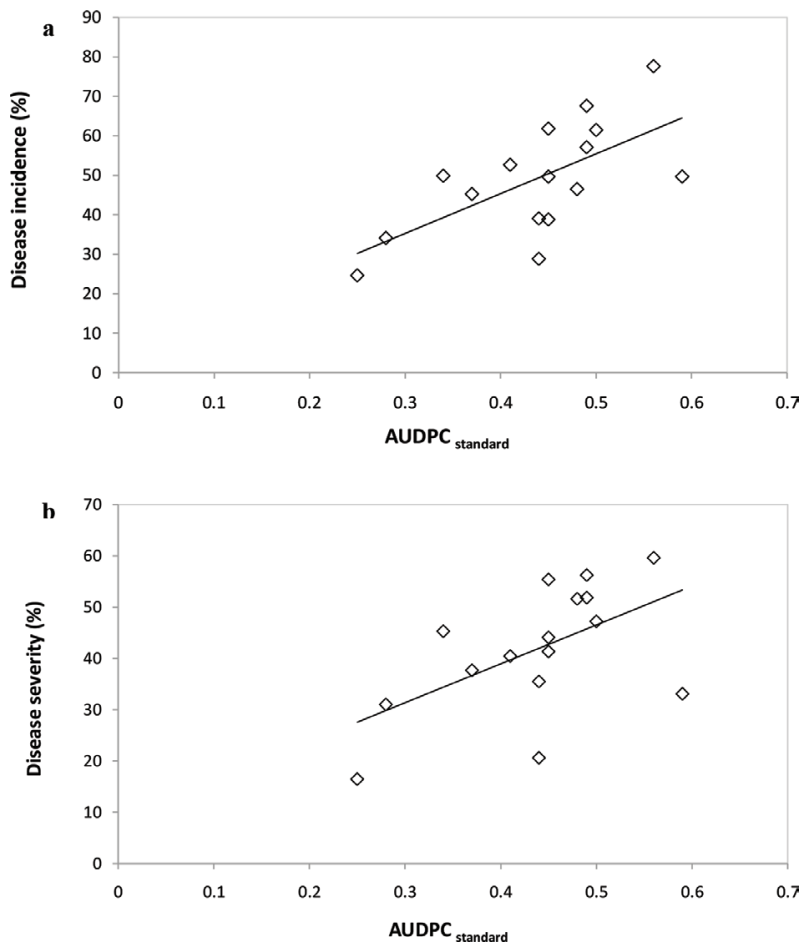

Fig. 4. Correlation between standardized area under disease progress curve ( $\left.\mathrm{AUDPC}_{\text {standard }}\right)$ (data presented in this study) and disease incidence of head inoculation in growth chamber (a) and disease severity of floret inoculation in growth chamber (b) (Sakr, unpublished data) on Triticum aestivum wheat cultivar Douma4 infected with 16 fungal isolates of four filamentous

Fusarium head blight species determined by Pearson correlation coefficient, $\mathrm{r}=0.653, \mathrm{P}=0.01$ (a) and $\mathrm{r}=0.559, \mathrm{P}=0.05$ (b) 
our previous analysis on the behavior of Douma4 in an in vitro (Sakr, 2017b) and in a growth chamber (Sakr, 2017a) assays. Taking into account that alternative sources of resistance have been screened in bread wheat to identify resistance donors for breeding (Xu and Nicholson, 2009; Steiner et al., 2017); Douma4 (bread) could be considered as promising resistance sources to FHB for introgression in the adapted wheat gene pool.

This work supports the view that the correlations of different pathogenicity indices exist and are stable with in vitro and in planta pathogenicity assays. The values of disease incidence and disease severity involved in artificial inoculations under controlled conditions (Sakr, unpublished data) were significantly correlated with AUDPC $_{\text {standard }}$ obtained in the current research: ( $\mathrm{r}=0.653^{*} *$ and $\mathrm{r}=0.559^{*}$, respectively) (Fig. 4). Results indicted that the Petri-dish pathogenicity test conducted on other FHB species is repeatable with bread wheat plants in a growth chamber. The in vitro assay can recognize the level of pathogenicity of four FHB species at early stages of plant growth by promoting the interaction between wheat tissues and fungi. The situation in the Petri-dish assay was identical to in planta artificial inoculation. FHB inoculum was put directly on the wheat seeds and they could directly penetrate and infect germinating seeds. Thus, disease development is manifested through appearance of symptoms such as brown necrotic spots on the coleoptiles and/or by mycelium completely covering the seeds. AUDPC $_{\text {standard }}$ could be of potential use in evaluating the pathogenicity of filamentous FHB in adult plants.

\section{Conclusion}

Pathogenicity may be expressed on the level of interaction on Syrian T. aestivum

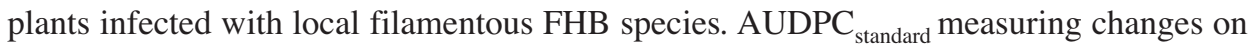
the level of pathogenicity could be used to evaluate the level of co-evolution of FHB complex with its bread wheat host. Recovery of FHB isolates from different Syrian locations could be essential due to high similarity in pathogenic level among the tested fungal isolates. The idea of using AUDPC $_{\text {standard }}$ appears to be based on their predictive ability of FHB disease impact in adult plants. Since only one Syrian bread wheat cultivar was tested here, further research using a large sample of available Syrian wheat cultivars is needed to validate our results in vitro, under controlled and field conditions.

\section{Acknowledgements}

The author would like to thank the Director General of Atomic Energy Commission of Syria and the Head of the Agriculture Department for continuous support throughout this work.

\section{Literature}

Alazem, M. (2007): Evaluating genetic variation of Fusarium head blight by molecular markers [Dissertation]. [Damascus: DAM], University of Damascus.

Bakri, Y., Jawhar, M. and Arabi, M. I. E. (2012): Correlative analysis of Fusarium species pathogenicity and in vitro xylanase activity. J. Plant Biol. Res. 1, 86-92. 
Bushnell, W. R., Hazen, B. E. and Pritsch, C. (2003): Histology and physiology of Fusarium head blight. In: K. J. Leonard and W. R. Bushnell (eds): Fusarium Head Blight of Wheat and Barley. APS Press, St. Paul, pp. $44-83$.

Brennan, J. M., Fagan, B., Van Maanen, A. et al. (2003): Studies on in vitro growth and pathogenicity of European Fusarium fungi. Eur. J. Plant Pathol. 109, 577-587.

Dahl, B. and Wilson, W. W. (2018): Risk premiums due to Fusarium Head Blight (FHB) in wheat and barley. Agric. Syst. 162, 145-153.

De Oliveira, E. A. D. (2014): The physiology and productivity of wheat (Triticum Aestivum L.) under elevated carbon dioxide concentration, high temperature and terminal drought. University of Western Australia, Crawley, pp. 1-178.

FAO/WFP (2015): Crop and food security assessment mission to the Syrian Arab Republic. [cited 2015 July 23] Available from: http://www.wfp.org/foodsecurity/reports/CFSAM.

Kiseleva, M. I., Ovsyankina, A. V., Kolomiets, T. M. et al. (2016): Some aspects of the distribution of Fusarium on cereals of Russia. Acta Phytopathol. et Entomol. Hung. 51, 183-191.

Nelson, P. E., Toussoun, T. A. and Marasas, W. F. O. (1983): Fusarium Species: An Illustrated Manual for Identification. The Pennsylvania State Univ. Press, Pennsylvania, pp. 1-193.

Parry, D. W., Jekinson, P. and MCleod, L. (1995): Fusarium ear blight (scab) in small grain cereals - a review. Plant Pathol. 44, 207-238.

Purahong, W., Alkadri, D., Nipoti, P. et al. (2012): Validation of a modified Petri-dish test to quantify aggressiveness of Fusarium graminearum in durum wheat. Eur. J. Plant Pathol. 132, 381-391.

Romero, C. C. T., Vermeulen, J. P., Vels, A. et al. (2018): Mapping resistance to powdery mildew in barley reveals a large-effect nonhost resistance QTL. Theor. Appl. Genet. 5, 1031-1045.

Sakr, N. (2017a): Aggressiveness of four Fusarium head blight species on wheat cultivars. Adv. Hortic. Sci. 31, 199-203.

Sakr, N. (2017b): In vitro assessment of Fusarium head blight spp. on wheat cultivars. Arch. Phytopathol. Plant Protect. 50, 254-261.

Sakr, N. (2018a): Aggressiveness of Fusarium head blight species towards two modern Syrian wheat cultivars in an in vitro Petri-dish. Cereal Res. Commun. 46, 480-489.

Sakr, N. (2018b): Aggressiveness variation among and within Fusarium head blight species on barley in vitro. Acta Phytopathol. et Entomol. Hung. 53, 1-10.

Sakr, N. (2018c): Components of quantitative resistance in barley plants to Fusarium head blight infection determined using three in vitro assays. J. Plant Protect. Res. 58, 176-183.

Sakr, N. (2018d): Evaluation of two storage methods for fungal isolates of Fusarium sp. and Cochliobolus sativus. Acta Phytopathol. et Entomol. Hung. 53, 11-18.

Steiner, B., Buerstmayr, M., Michel, S. et al. (2017): Breeding strategies and advances in line selection for Fusarium head blight resistance in wheat. Trop. Plant Pathol. 42, 165-174.

Xu, X. and Nicholson, P. (2009): Community ecology of fungal pathogens causing wheat head blight. Annu. Rev. Phytopathol. 47, 83-103. 